\title{
MapOnLearn: The Use of Maps in Online Learning Systems for Education Sustainability
}

\author{
Sannyuya Liu ${ }^{1}$, Dongpo Guo ${ }^{1}$, Jianwen Sun ${ }^{2}$, Jie $\mathrm{Yu}^{3}$ and Dongbo Zhou ${ }^{2, *}$ \\ 1 National Engineering Research Center for E-learning, Central China Normal University, Wuhan 430079, \\ China; lsy5918@ccnu.edu.cn (S.L.); guodp@mails.ccnu.edu.cn (D.G.) \\ 2 National Engineering Laboratory for Educational Big Data, Central China Normal University, \\ Wuhan 430079, China; sunjw@ccnu.edu.cn \\ 3 Office of Scientific Research and Development, Wuhan University, Wuhan 490070, China; \\ yujie_gsis@whu.edu.cn \\ * Correspondence: zhoudongbo@ccnu.edu.cn
}

Received: 2 August 2020; Accepted: 24 August 2020; Published: 28 August 2020

check for updates

\begin{abstract}
Online learning and teaching have become the primary forms of education during the global pandemic, and online learning systems, which can provide fair educational opportunities for everyone, are increasingly important for sustainability in education. The amount of time a student spends on online learning systems affects the fairness and persistence of sustainability in education. To support personalized learning opportunities, interactive learning, and easy-to-access resources, we propose a map organization and visualization method called MapOnLearn for online learning systems. First, we converted tree-like hierarchical course units (HCUs) and knowledge points (KPs) into a fundamental two-dimensional (2D) map of hierarchically divided polygons and used the map to form containers to manage all learning resources. Then, we used the zoom feature of the map to express the hierarchical structures of knowledge and formulated corresponding rules for displaying information at different levels. Path analysis was applied to express the learning process, and topological processing was adapted to represent the relationships among HCUs and KPs. We developed maps for a high-level math course, a course on data structures, and an English course at a university in China and investigated 264 students and 27 teachers for a semester by using the technology acceptance model (TAM). We found that the map visualization and organization method had a positive impact on the way teachers and students use online learning systems and improved the online learning experience. To attract more students to spend more time on online learning, we hope our method can promote the sustainable development of education.
\end{abstract}

Keywords: education sustainability; online learning system; map usage; learning resource organization and visualization; higher education; TAM

\section{Introduction}

Massive open online courses (MOOCs) and online learning systems are becoming increasingly important all over the world, especially due to emergency public health incidents such as COVID-19, which has strictly limited the actions of teachers and students. Online learning systems can provide fair educational opportunities for everyone and are increasingly important for sustainability in education. The amount of time a student spends on online learning systems affects the fairness and persistence of sustainability in education. However, the clarity of course units and learning content, the simplicity of visualizations, and the accessibility of adaptive resources for online learning affect the use of such systems [1].

Hierarchical directory structures and tables cannot be used to sufficiently manage course units and arrange teaching or learning resources [2]. It is difficult for learners to retrieve the relevant 
resources of the hierarchical course unit (HCU) from tree-like or node-link style diagrams because small node-based shapes and dense lines are hard to select at small scales. The students and teachers complained about the terrible experience and the complicated interface, which led to a low completion rate for online learning courses [3]. Students need to be more active in maintaining their own progress by, for example, identifying the content that can best help them reach their learning goals [4]. Browsing-based learning and location-based navigation are expected to dominate the online learning experience [5]. Visualization-based learning for online learning systems has been a popular research topic for years [6]. Among those applications, the map-based container played an important role in resource management, and it created a visible framework that can support a browsing-based clickstream learning method [7]. When online learning adopts features such as zooming, selecting, and panning, such learning methods will become more attractive, as learning path navigation and personalized progress maps will increase convenience. Interestingly, maps can be used for hierarchical course units (HCUs) to support online learning in a manner similar to public map services such as Google Maps [8]. Maps can organize and display HCUs and knowledge points (KPs) as cartographical objects using geographical metaphors, and the map elements include a series of signs, symbols, graphical primitives, and location information, such as annotations, shapes, colors, positions, distances, and areas [9]. With the development of location-based services (LBSs), the map method has become increasingly crucial for the recommendation of learning content [10] and the facilitation of teaching/learning processes [11], ubiquitous teaching services, and e-learning systems.

Cartographic principles have been applied to build a map-like online learning system [12]; however, HCUs have not yet been mapped to symbols or represented as shapes in the research. In this paper, we propose MapOnLearn, a mapping method for organizing and visualizing HCUs and KPs for online learning. MapOnLearn uses a mapping method to generate a location-based map for HCUs, and it supplies a map navigation learning experience that describes learning progress and redirects to learning resources.

In view of the existing online learning platforms, we found the tabular style organization of learning resources in a coarse granularity makes it hard to attract the students, in a lasting way, to finish the course without mandatory learning requirements. The target of this paper was to try to applying the usage of maps in daily life into the online learning environments. We first developed the map method to manage the online learning resources, then we supplied a map-based online learning platform for serval courses. We hope our map style online learning platform will be more attractive, more interesting, and more convenient.

The contributions of this paper are as follows. First, we propose a map generation method by using independent quaternion information to convert HCUs into a fundamental 2D map. The area-based map units of cells were associated with the HCUs and KPs. The cells of KPs were further divided into Voronoi polygons, which were then assigned to the related learning resources. Second, we applied scale visualization, path finding, and topological processing to represent the hierarchical information and relationships of the CUs. Furthermore, map exploitation operations, such as panning, zooming, and selecting, were integrated to support learning through a web browser. Finally, we evaluate this method for education sustainability.

\section{Literature Review}

\subsection{Resource Organization and Visualization in Online Learning}

Due to the rapid development of online learning systems, resources and materials must be updated. Common methods for organizing the resources of online learning systems include syllabi-based tabular links and pages, which manage HCUs and treat related resources as supplements or appendices in the form of exercises or homework [13]. Sobreira stated that the syllabi-based tabular organization and visualization method was a flexible and easy-to-use method for K-12 teachers and university lecturers [14]. This method is mainly applied in teacher-centered online learning systems such as 
mobile social learning platforms [15], most MOOC platforms [16], and virtual lab education [17], but it is not good enough for student-centered systems [18]. The materials and content of the course based on the experience of the teacher are listed in the appendix [1]. Therefore, the teaching and learning procedures are not adjustable and the resources are based on the experience of the course instructors. The syllabi-based tabular method is popular for problem-based teaching [19] and problem-solving environments [20], which aim to collect students' collaborative study activities and physical interactions [21], and teaching resources, students' computational practice, and interaction results are collected in a table or list [22].

The learning management system (LMS) is a popular method used for learning resource organization, and it is broadly adopted to support teaching activities [23], to collect students' online behaviors [24], and to predict academic performance [25]. These software programs provide learners with a browser-based environment they can use to review course objectives, download course materials, and submit assignments through hyperlinks that are dynamically added to or removed from the webpage based on resource availability [26].

Moodle is commonly used in online learning for teacher-oriented course management [27] and student-oriented learning contents planning [28]. This tool has five kinds of static course materials and eleven kinds of interactive course materials arranged by the social constructionist pedagogy. For personal learning management, a dashboard is used as a visual user interface (UI) to provide a progress overview [29] and statistical information via graphs, gauges, and dials [30]. However, the visualization of such content on a dashboard is an open issue for various system targets. It is also difficult to redirect to or access the correct learning resource through the dashboard [31].

\subsection{Map Methods for Online Learning}

Map organization and visualization methods for online learning can be classified into two categories. The first category includes diagram representations such as concept maps, mind maps, cognitive maps, and knowledge maps. A concept map [32] represents a course as a diagram. The nodes of the diagram represent concepts, and the links show the relationships among nodes [33]. The teaching and learning resources are attached to the corresponding nodes of the concept map [34]. Therefore, concept maps can promote learning [35]. Mind maps and brain-main maps depict conceptual content using short phrases, while arrows, lines, or cross-links are used to represent the relationships between conceptual phrases. Such diagrams can be used to show knowledge structures or schemas as well as the student's progress after instruction [36]. A cognitive map is a map that represents the spatial arrangement between objects in a physical environment. Such maps are built based on various contextual cues that represent the visual elements and surrounding elements such as illustrations, notes and highlights, and hyperlinks are used to organize the text. Cognitive maps benefit online learning by providing the location of the book, and they promote the retention and recall of textual information [37]. Knowledge maps (KMs) are receiving increasing attention; however, it is unclear how to use them to visualize knowledge from different perspectives [38]. The methods used to visually represent existing information can be categorized into one-dimensional (1D), two-dimensional (2D), three-dimensional (3D), multi-dimensional [8], and tree-based methods. The 1D method displays the objects in a linear manner by employing $1 \mathrm{D}$ objects to represent abstract information. The 2D method displays information as 2D visual objects, and the 3D and multi-dimensional representations use 3D objects and 2D planes to display objects generated by dimensional reduction, respectively. The tree-base map method, which employs a hierarchical structure that can fully utilize an available space, has become a popular technique for visualizing hierarchical data. The space-filling generation approach [39], the cone-tree [40], and other methods use the bounded aspect ratio [41] and Voronoi algorithm [42] to optimize polygons in terms of stability. The visual forms of KMs can be classified in terms of hierarchical display mode, network display mode, and map display mode. The hierarchical display mode can provide users with both global and local views of information by organizing and representing information in different levels and branches according to concept and approximation [11]. 
The network display mode uses nodes to describe concepts and links to represent the relationships between concepts to help users make inferences [43]. The map display mode can provide a more comprehensive and convenient view than both hierarchical and network displays [44].

The second category includes digital maps and public LBSs such as Google Maps or ArcGIS map services. Digital maps have been used for teaching and learning geographical subjects and associated topics for years [45], and currently, browsing and interpreting maps are considered to be general skills for tasks in daily life such as taking a taxi and ordering takeout. By using cartographic representations, geospatial objects can be integrated into learning resources. Many e-learning systems use online mapping services such as the Google Maps Applications Program Interface (API) to organize and visualize information. Khan Academy provides a concept-map navigator based on Google Maps API but fails to balance local and global views [46]. In the domain of bioinformatics, protein interaction [47] and genome projector [48] visualize multiscale structures by using the map scale of Google Maps API. Moreover, the functions of location-based systems and services are applied to help the learning systems to locate resources, track users, make recommendations for learning, and visualize information. Mobile learning systems apply LBSs to track users [49], especially when users are outside. Wandering platforms create interactive location-based learning objects that support the exploration of new information and interactivity with the environment [50]. Fusing sentimental and spatial contexts, Zhao proposed a personalized location recommendation system [51]. By using location-based social networks to record the users' behaviors, NationTelesope can monitor and visualize collective behaviors at a large scale [52].

In summary, online learning systems widely use syllabi-based tabular organization and visualization methods to manage online learning and map methods with diagram representations or digital map services are not integrated with the content of the course. These methods fail to support the increasing demands for personalized learning. Therefore, new management and visualization methods for online learning are needed to facilitate usage and attract learners.

\section{Materials and Methods}

Our proposed method uses a 2D map to organize and manage teaching and learning resources. The main steps and notations of the proposed method are shown in Figure 1.

The first step is to select courses and prepare the data. For most college courses, the units and KPs are structured as a tree-like table of contents. Considering representative curricula in higher education in China, we selected a high-level mathematics course, a data structures course, and an English course. The mathematics course contains all HCUs in higher education, and the data structures and English course units include many learning elements that are not words.

The second step is map generation. We gave an HCU and KP representation and developed the division algorithm to convert the knowledge tree into a 2D map. We adapted a representation of four independent values for each HCU and KP for parameter processing. We first examined the levels and relationships by designing a data structure for storage. Then, we obtained the pedagogical information and evaluation information regarding the difficulties of each KP in the courses through discussions with teachers at the schools. The values reflect the actual pedagogical process based on years of teaching. We also automated value generation, which avoided a lot of manual work.

The third step is map organization. We first developed a partition method to divide the region and then applied the positioning method to coordinate each HCU and KP. The hierarchical directory structure of the HCUs and KPs was mapped into a 2D regional space via top-bottom partitioning. After that, the area-based map units of cells were associated with the HCUs and KPs. The cells of KPs were further divided into Voronoi polygons, which were assigned to the related learning resources.

The fourth step is map visualization. A geo-reference system was selected to assign to each object in the map; therefore, the map could be integrated with public geospatial services such as Google Maps. We used scale controlling to determine which level should be visualized during the study. A coarse level corresponds to a small scale and a fine level corresponds to a large scale. A scaling mechanism was adapted to visualize the appropriate information during the learning process. Then, each polygon 
and line underwent a topology check to ensure uniqueness and to prevent geometrical overlay. Thus, we can obtained a unique path for the analysis of learning progress. To create a high-quality map visualization, we balanced the color of the map and ensured that the shapes used to represent KPs were meaningful. The criteria for color and shape (discussed hereafter) are based on cognitive theories in cartography and cognitive psychology. In this paper, a commonly used cartographical style was taken from the GIS software QGIS.
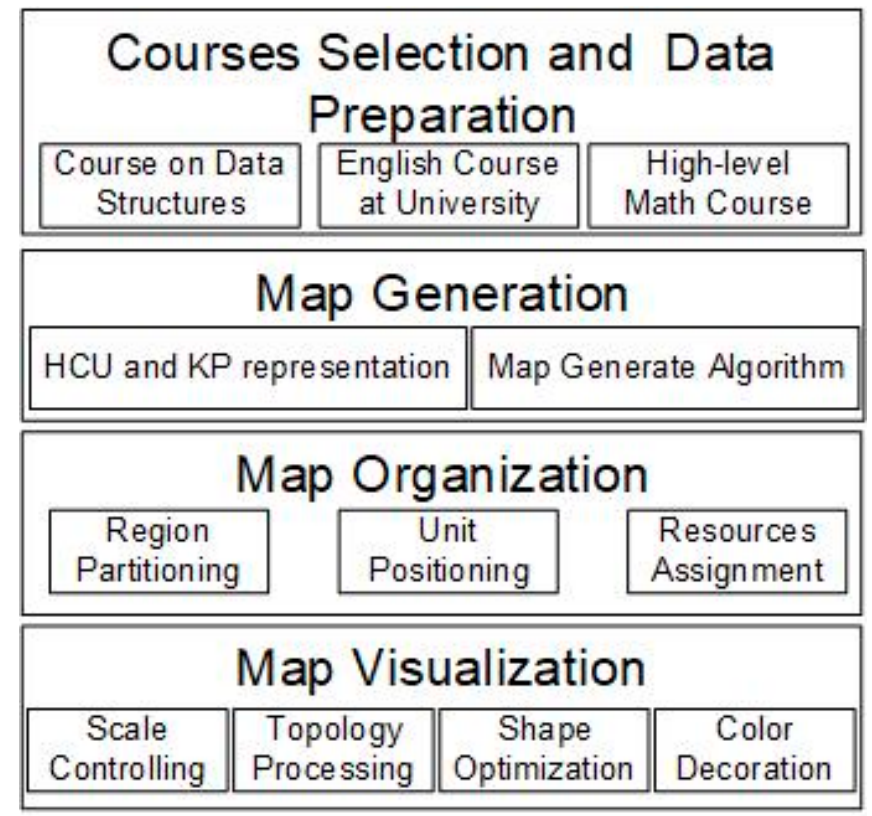

\begin{tabular}{|c|c|}
\hline \multicolumn{2}{|c|}{$\begin{array}{c}\text { Map Usage and Sustainability } \\
\text { Evaluation }\end{array}$} \\
\hline $\begin{array}{c}\text { Examples of Map } \\
\text { Usage }\end{array}$ & \begin{tabular}{|c|}
$\begin{array}{c}\text { Evaluation of Online Learning for } \\
\text { Education Sustainability }\end{array}$ \\
\end{tabular} \\
\hline
\end{tabular}

Figure 1. The main steps of the map organization and visualization method for online learning systems. First, we selected three typical university courses: a data structures course, an English course, and a high-level math course. Next, we generated the map for the online learning system. Then, we used the map to organize the resources of the online learning system. We applied scale control, topology processing, and shape optimization to visualize the online learning system. Finally, we gave examples of map-based online learning and evaluated feedback from students and teachers.

Finally, we tested the use of the map for online learning with three courses and evaluated feedback from students and teachers regarding the map-based online learning system.

\subsection{Course Selection and Data Preparation}

To consider different requirements and learning experiences, we chose three different courses for online learning. The first was a data structures course, which is the fundamental course for computer science. The second course was a high-level math course that is a compulsory course for engineering students. The third course was an English course that is a public course for freshman in universities of China. These courses form the foundations of different majors. The courses have different requirements and difficulties, and the learning processes are monotonous and increase in difficulty over the duration of the term; thus, some students may give up halfway through a course. The resources used for all students are not appropriate for the different levels of students in a uniform platform.

In this paper, we first constructed the course knowledge graph by analyzing the HCUs and KPs to represent the different levels of the knowledge graph. We collected learning resources from different 
teachers and then set up the resources related to the KPs. Unlike MOOCs, we collected many learning resources from different teachers for one $\mathrm{KP}$, including videos, presentations, voice records, textbook pages, pictures, exercises, and microclasses. These resources need to be organized and managed to support the requirements of personalized learning.

\subsection{Map Generation}

\subsubsection{HCUs and KPs Representation}

In this section, we present a new description model called the independent quaternion structure (IDS) for HCUs and KPs. The four elements of this model are independent, and they are not correlated.

$$
\mathrm{Q}(\mathrm{H}, \mathrm{R}, \mathrm{V}, \mathrm{C})
$$

Equation (1) defines the structure as a set description. Here, $Q$ is the quaternion structure, $\mathrm{H}$ represents the hierarchical relationship information of HCUs or KPs, R represents the association relationship of HCUs or KPs, V represents the information volume of HCUs or KPs, and C represents the category of the HCUs or KPs.

The hierarchical relationship information represents the level numbers of the HCUs in the hierarchical levels, which range from 0 to the largest number of levels. The contained relationship of the HCU is also described with this parameter.

The hierarchal structure is typically visualized using a tree view, such as a directory tree. In the textbook, the hierarchy includes grade, semester, chapter, section, and unit levels. Herein, grade is the root level; semester, chapter and section are levels 1 to 3, respectively; and the unit is the leaf level. The root and leaf levels are fixed for most of the highest and lowest levels, respectively. The numbers of the middle levels (i.e., levels 1 to 3 ) depend on the method used.

To automate this process, the hierarchical relationship for every node in the tree is described as a constructing number. Initially, the root level is set to 0 . Travelling in a breadth-first manner, the child will add the parent code first, and then, the sequence of numbers will be added following the parent number. For example, grade will be set to 0 , semester will be set to 01 , and third chapter will be set to 013 (see Figure 2).

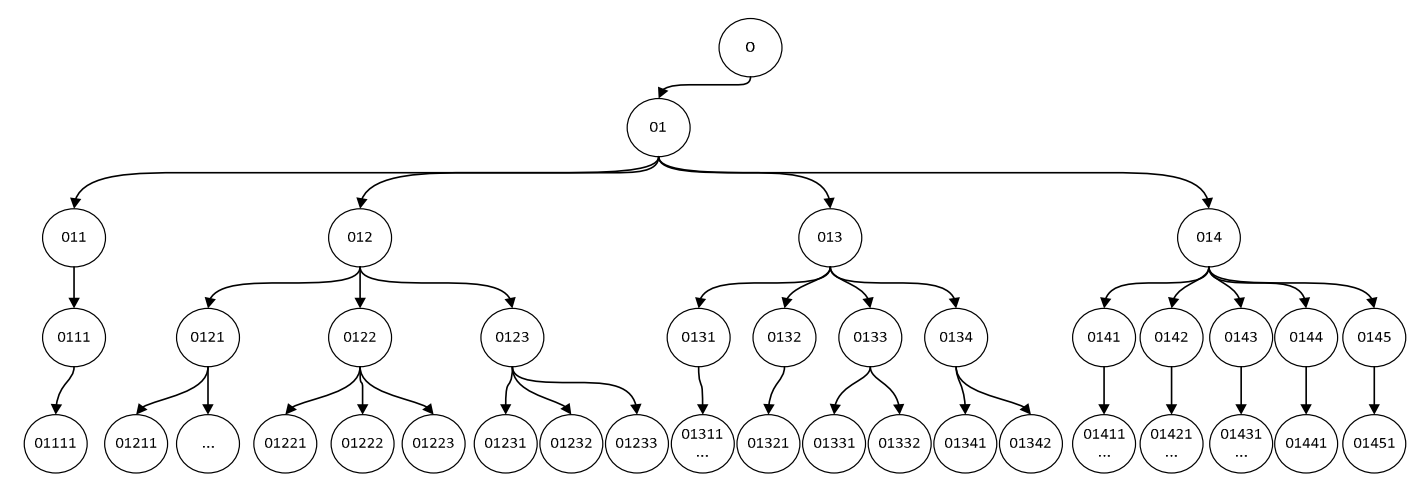

Figure 2. A sample of the code generation for the hierarchical information: 0 is the topmost level, and the child levels will add the code of the parent level before the code in each level. This method will generate $\mathrm{H}$ for each unit.

The association relationship information includes the time-series relationship and dependency relationship between HCUs on the same level. Specifically, it reflects the order in which the HCU should be taught or studied. The time-series and dependency relationship in this paper was defined as the order and dependency of the HCUs on the same level of the hierarchical structure. We used numerical order to represent the value of the relationship. For example, if there are 5 HCUs in the 
current level, and the HCUs are arranged in order, then the values will be set from 1 to 5 for the HCUs based on the sequence.

The information volume (IV) is used to represent the content in each HCU. IV is used instead of entry or other information, and it functions as a measurement, like the length of time spent on teaching or studying. We defined the information volume as a uniform value that can be compared and measured in application. The information volume of one HCU is its number of HCUs. The value of each HCU can be assigned during the second stage when the teachers evaluate each HCU. Then, the values of the parent HCUs can be calculated in a bottom-up manner.

We established the following code for the main categories (C) and subcategories: 1 for factual knowledge, 2 for conceptual knowledge, 3 for procedural knowledge, and 4 for metacognitive knowledge. The values set for the activities were 1 for remembering, 2 for understanding, 3 for applying, 4 for analyzing, 5 for evaluating, and 6 for creating. For example, conceptual knowledge to be remembered would have a code of 21 , while metacognitive knowledge to be analyzed would have a code of 44 . The categories were set during the teachers' evaluation in the first stage.

In the preparation stage, the evaluation information of the HCU will consist of the information volume and HCU category. The teachers will provide a value based on the definition. We will clearly state that, if the values for the information volume and HCU category are set at random, then a map can be generated; however, we used the teachers' values based on their experience to generate a more reasonable map. This method does not need guaranteed values for the parameters.

\subsubsection{Map Generation Algorithm}

In the beginning of the map generation stage, we determined the map area using four corner points with longitude and latitude values. Theoretically, one can choose any value from $[-180,180]$ for the longitude and from $[-90,90]$ for the latitude based on the requirement that the four points form a rectangle. Taking the projection into account, the latitude will be limited to $[-65,65]$ because larger projection errors are associated with values between $[-90,-65]$ and $[65,90]$. We used World Geodetic System 1984 (WGS 84) as the geo-reference system.

The algorithm begins by traversing the hierarchical tree along its breadth. Then, the area is partitioned based on the node. For the top node, the area is the total area, which can be partitioned into several small parts based on the number of children. The coordinate of each child node is calculated via a space-filling curve based on $\mathrm{V}$. The shape of the child map is determined by the category information c. Finally, each map element is decorated based on cartographic principles.

The area partition follows a top-down approach to divide the map area into different parts based on level. That is, at the top level, there is only one root node, which is set to the total area. At the second level, suppose there are 3 children or subunits, then, the area will be divided into 3 parts, and each part will be assigned to one child or subunit. For each subunit, the same steps will be followed to partition the area into parts based on the number of subunits. The process will terminate when all leaf units have corresponding areas.

To avoid an extremely narrow area for the HCUs at each level, additional rules are added. These rules are related to the ratio of the length and width of the resulting shapes and specify that the resulting area should correspond to the number of subunits; thus, as the number of subunits increases, the area also increases. In the partition method, the summation of the areas of the subunits is set equal to the unit area. Therefore, we can use the volume to simplify the calculation.

The coordinate generation step will determine the coordinates for each HCU. A space-filling curve method is employed to calculate the position in 2D, in which $\mathrm{V}$ is one of the most important values for identifying the position in the curve. The curve can be any type of 2D space-filling curve, such as the Hilbert Curve or Z Curve. We implemented the Hilbert Curve in our study. The coordinates of the HCU can also be generated by using a grid partition; we implemented this method as an alternative, as it is simple, with low computational complexity, especially when the regular cell partition method is used. The coordinates $(x, y)$ represent the position of the center point of the grid. 
Once we obtained the area and position of the HCU in the final map, the shape of the map object needed to be formatted based on the category information and volume information. Previously, we used a simple shape, such as a rectangle, circle, triangle, or regular polygon. We bound one shape to each category, and the size of the shape was determined by the volume.

We provide examples of the definitions used in our implementation in Table 1. In this table, factual knowledge is represented by a regular triangle, conceptual knowledge by a regular rectangle, procedural knowledge by a regular pentagon, and metacognitive knowledge by a regular hexagon. It should be noted that the shapes can be different; here, we are simply providing an example for demonstration. For a regular shape, a public polygon generation method is used.

Table 1. Binding shape definitions.

\begin{tabular}{cc}
\hline Category & Shape \\
\hline 1 (Factual Knowledge) & Regular Triangle \\
2 (Conceptual Knowledge) & Regular Rectangle \\
3 (Procedural Knowledge) & Regular Pentagon \\
4 (Metacognitive Knowledge) & Regular Hexagon \\
\hline
\end{tabular}

Factual knowledge is represented by a regular triangle, conceptual knowledge by a regular rectangle, procedural knowledge by a regular pentagon, and metacognitive knowledge by a regular hexagon.

The size of the shape is determined by the information volume of each unit, which is used to calculate the bounding box of the shape. The size of this box limits the radius of the circumscribed circle, and the radius is used to calculate the length of the regular polygon.

\subsection{Map Orgnizatoin and Learning Resource Organization}

After map generation, the tree-like directory is converted into a 2D map. The finest polygon represents one KP. As described previously, the learning resources are related to the KP; thus, we needed to assign containers to hold the resources of the KP. For the polygon of the KP in the map, we needed to generate small items to corresponding to the learning resources.

There are several ways to build the items for one polygon to hold the resources. In this paper, we applied two methods to produce two different outputs, as shown in Figure 3. First, we generated many small rectangles in the polygon of the KP (Figure 3 (left)). The number of rectangles is equal to the number of resources, and the size of each rectangle was calculated according to the ratio of the numbers and areas of the polygon of the KP. The more resources, the smaller the rectangles and the worse the result. Second, we divided the polygon of the KP into Voronoi polygons based on the quantities of the learning resources. Figure 3 makes an example of the higher math KP of scale. We collected serval learning resources, such as presentations, videos, and exercises, and we dynamically partitioned the cell into Voronoi polygons that correspond to the resources (Figure 3 (right)).

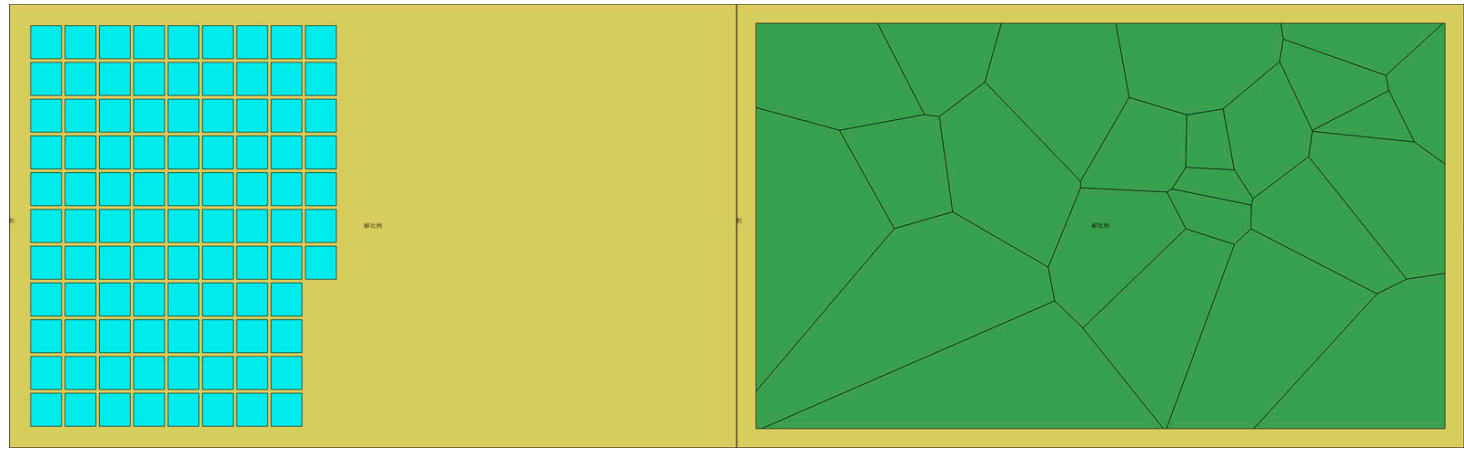

Figure 3. Voronoi partition of a knowledge point (KP) based on the number of materials. The blue blocks on the left refer to materials, and each Voronoi polygon of the right is assigned to one resource. 
Voronoi polygons are dynamically regenerated when the number of learning or teaching resources changes. The size of the Voronoi polygon can be adjusted according to the importance of the resources. In our implantation, we set the number of visits as the value for each resource, and the more students, the larger the polygon. We used the recommended value of the teachers to initialize the size of the Voronoi polygons. In addition, we classified the resources, and the class was used to assign the color so that learners could focus on the items recommended for a class.

Specifically, the Voronoi polygons are generated based on the personalized information of the students, such as the visit information and the learning process. Therefore, the result of the map in the finest grain will be different for everyone; there will be the same number of polygons, but they will differ in terms of shape and color. We set a combination weight value to each resource of the $\mathrm{KP}$ when the resources for one KP had been decided. Then, we generated a lot of points so that the number was equal to the counts of the resources. We summed the weight value and made this value an integer, then got two integer numbers that produced just more than the sum value. The two numbers represented the row and column to divide the rectangle of KP. We scattered the points into cells according the weight value. After the Delaunay triangulation of the points, we generated the Voronoi polygon for the finest resource of the KP, and the point representing the resource was the center of the Voronoi polygon. A personalized polygon can be more suitable for personalized online learning.

\subsection{Map Visiualization Method for Map-Based Online Learning}

When the map is built and the resources are managed, the map can be used to support online learning with the help of map operations. The zooming operation can be used to display different levels of detail. For a fine-grain view of the KP, we zoom in, while for coarse HCU, we zoom out. Selecting and querying operations can be used to get a special KP or HCU. By clicking the leaf mouse on the map, learners can select a unit, a KP, or the resource at different scales or in the target scale. The map service supports name querying and position querying, and users can easily locate the resource.

To support complex usage, we used path-find to express the learning process or represent the learning path. The path-finding method was applied to get the learning path for the learner from a starting KP to an ending KP, as shown in Figure 4. We recorded the learning processes of the learners and then linked the sequence of the KPs to get the path. For the unlearned KPs, we used the hierarchical relationship information and the association relationship to find the neighbor KPs and the neighbor parent units from the start KP to the end KP. The linked line segments represent the path the learners should take.

To create a suitable map, the shapes and colors of the polygons in the map must be optimized by cartography. In fact, different colors may have different cognitive effects. However, there is a standard for maps in the field of cartography, especially for maps that are to be published. MapOnLearn aims to provide an online map service, and the color of each polygon adheres to the following rules: pink or light brown for residential areas, purple or light yellow for roads, blue for water systems, light green for vegetation, and dark green for annotations or labels.

During implementation, we used the information volume to identify the color, with higher values corresponding to darker colors. Polygons in darker colors were more difficult to learn, whereas those in lighter colors were easier. When polygons in the same color were adjacent to one another, cartographic principles were used to adjust the brightness or color component so that the polygons met the four-color separation principle.

To avoid obtaining the same shape for all HCUs, we applied fractal processing to the geometry to perturb the edges of the polygon. In this paper, a random number between 1 and 10 was generated to determine the number of times that the fractal of the edges was calculated. The perturbations of the edge may require further discussion. However, this paper describes only a possible, automatic method, not the reasoning behind it.

Another important component of cartography is symbol representation. In traditional methods, cities are represented by points of different sizes or other symbols based on their importance. 
For example, the capital of the country and large metropolises are shown as different types of circles: the capital is shown as a pentacle, and the metropolises are shown as concentric circles. Similarly, railway lines are shown as dashed lines to distinguish them from highways, which are drawn as parallel lines. Taking pictographic cognition into account, cartoon-like symbols can be useful for different age groups. Thus, cartoon-like symbols that consider gender and age can be developed based on widely known stories for such systems.

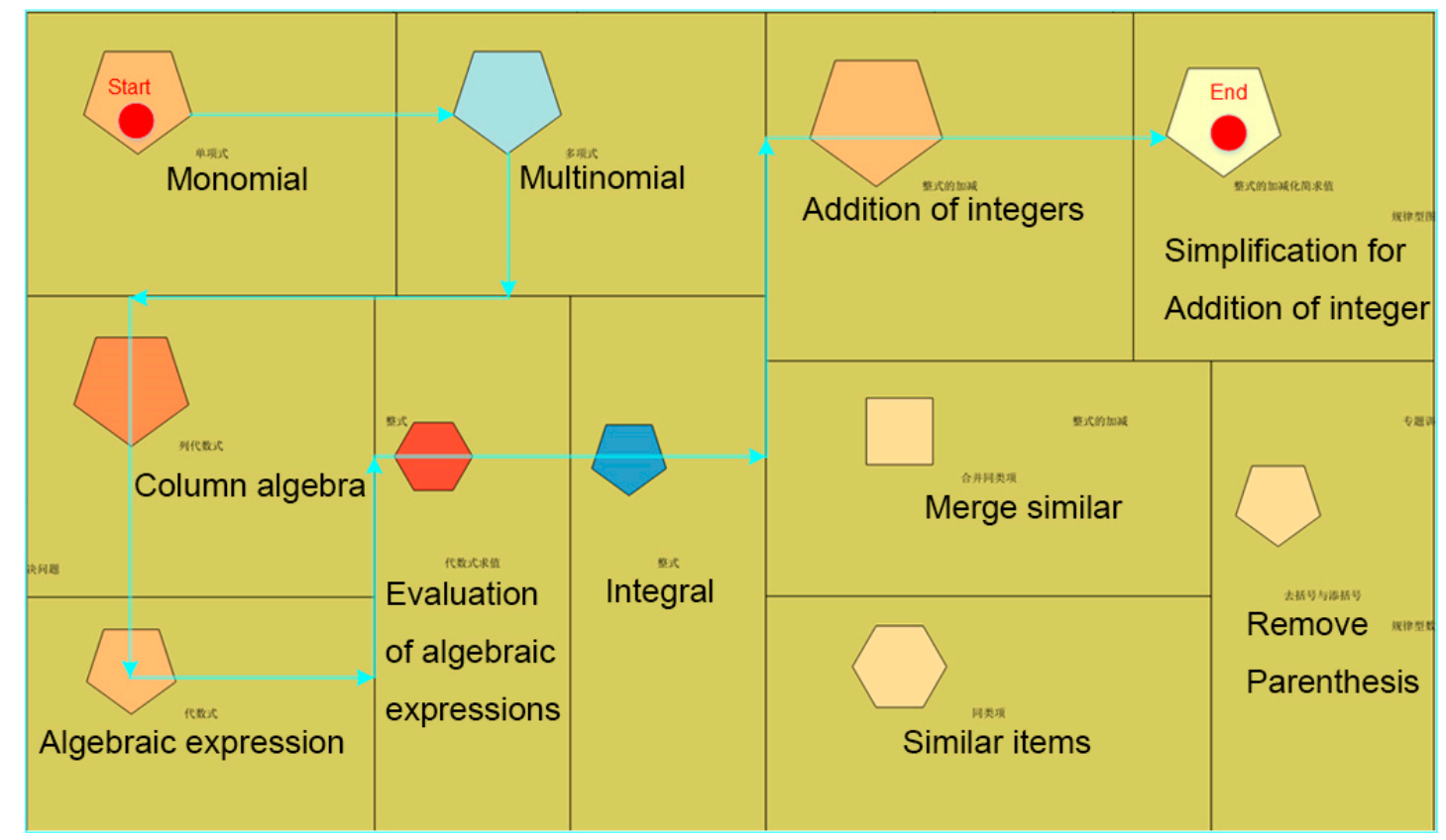

Figure 4. The learning path for one student developed by using the path-finding method. Given the starting KP and the ending KP, we aimed to find the learning path.

\section{Experiments and Results Analysis}

\subsection{Data Description}

During the development of a map organization and visualization method for online learning for college students, we tested three courses: a high-level mathematics course, a data structures course, and an English course. Figure 5 shows part of the hierarchical tree of the data structures course. The top node is the root, which identifies the course (e.g., data structures). We represented the data with several levels (i.e., grade, semester, chapter, section, HCU) according to the organizational structure. As mentioned, the method presented herein considers only the hierarchical structure, not the meaning of each level. The hierarchical tree of the original data was the table of contents of the course, which was extracted from the textbook published by the government education press of China. The levels of the tree may vary by book. We used an XML structure to store the information assigned by teachers. The tags of the XML file corresponded to the hierarchical levels. We added independent quaternions to each HCU as attributes. The values of the attributes could be assigned either manually or automatically.

We attempted to create the values for independent quaternions in two ways. First, we invited several well-known teachers with more than five years of teaching experience from the university in Wuhan to discuss their respective fields. We evaluated the category and volume information of each HCU. Second, automatic generation methods were developed for each course. To this end, we set up a random combinational generator. The first random number generator produced numbers between 1 and 4 to identify the categories, and the second random number generator produced numbers between 1 and 6 to identify the subcategories (e.g., factual, conceptual). The volume information is the total 
amount of time needed to teach an HCU in minutes. With the automatic method, values between 30 and 60 were randomly assigned.

The last data preparation step is the value check procedure. It is important to confirm that all HCUs have been assigned and that each node of the hierarchical tree has a correct value. Using a bottom-up approach, the sum of the volumes of the children was assigned to the parent node. The existing values for the knowledge category, associated relationship information, and hierarchical relationship information were checked. If no value exists or if the existing value was out of range, then the automatic method generated a reasonable value for the parameter. To ensure data reusability, we stored the results in XML files. Thus, when others use the configuration files, they can obtain the results of the test, and they can change the values to produce a new map.

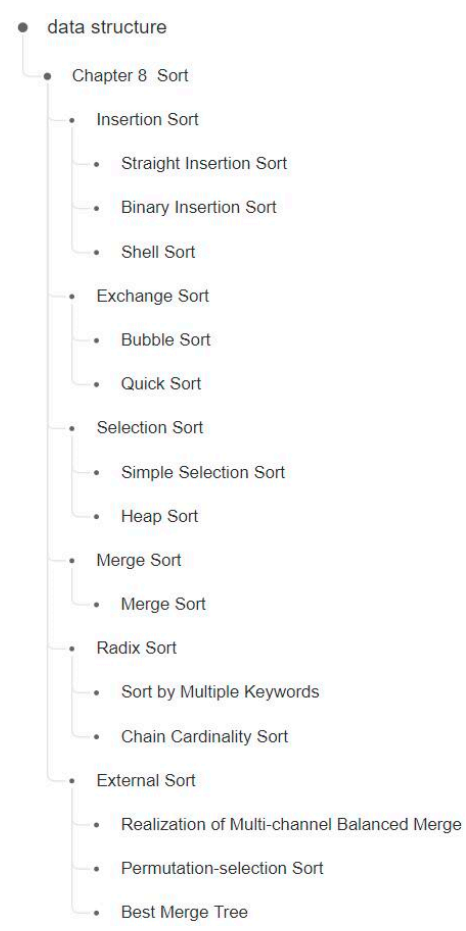

Figure 5. Hierarchical tree for the data structures course.

\subsection{Map Results}

A test platform was developed for this paper. We provided free copies of the software for different teachers. The teachers used the platform to prepare the original data and to automatically generate the map by importing the XML files.

Figure 6 displays the map generated for the mathematics courses. Different levels are shown on different scales. Thus, the map shows the first level (i.e., the root level) at a coarse scale, as shown in Figure 6A. When one zooms in while navigating the map, the middle levels will be displayed at a certain scale, as shown in Figure 6B-F, which correspond to levels 1, 2, 3, and 4 and the leaf level, respectively. The HCU is shown at the finest scale, and the area of this region must be further partitioned into small parts by using the Delaunay method. In this example, we simply set the shape of the middle levels as rectangles and assigned colors to different levels, with each part at the same level having a color that was determined by the volume information. The map elements are annotated at the levels that display the name of the node. At the leaf level, symbols are used to represent resources. 


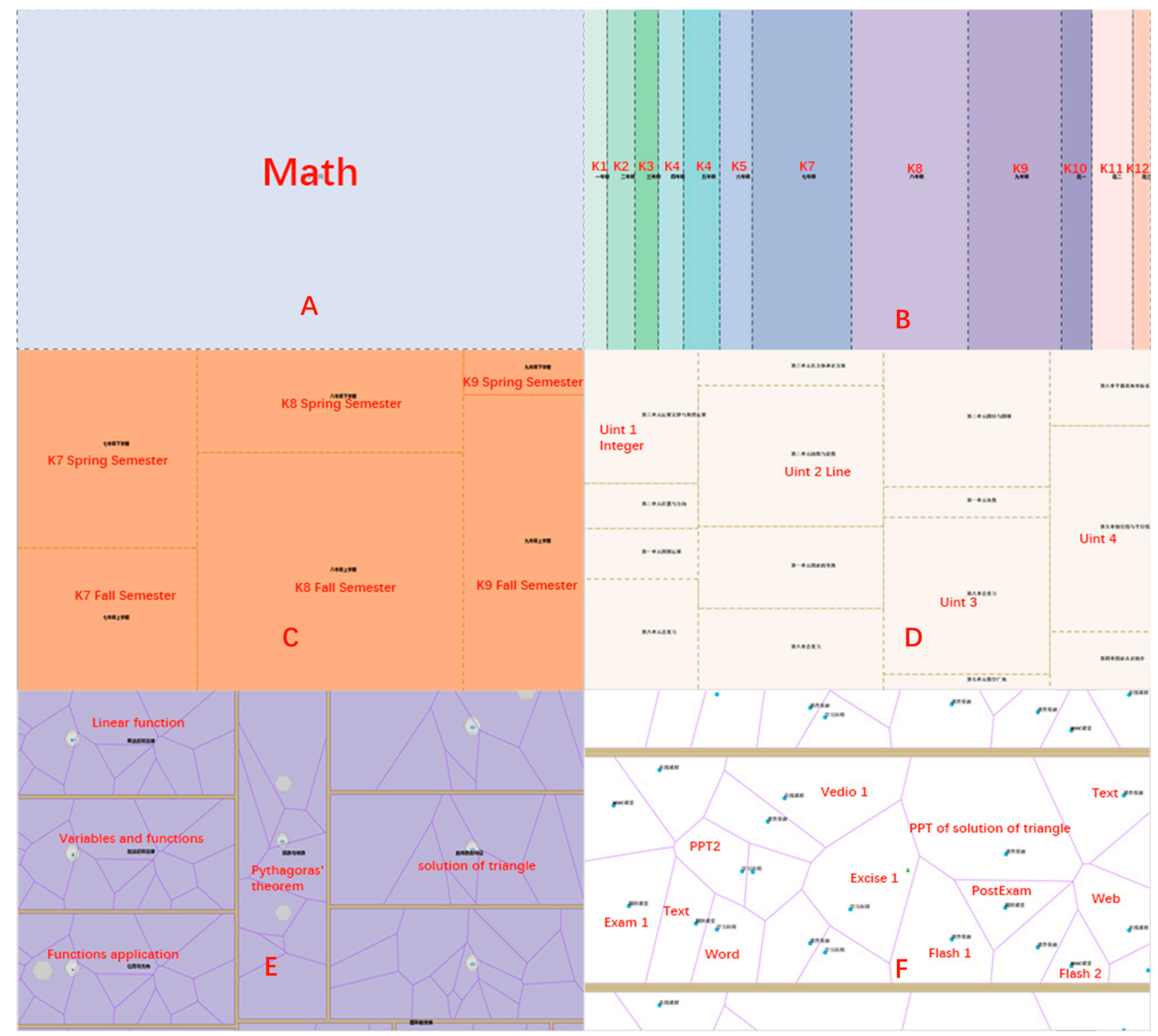

Figure 6. The map generated for the mathematics course. (A) is the top level, which corresponds to the root; $(\mathbf{B})$ is level 1, which shows the grade level of the hierarchical tree; $(\mathbf{C})$ is level 2, which shows the semester; (D) is level 3, which shows the chapter; (E) is level 4, which shows the section; and finally, (F) is the leaf level, which corresponds to the HCUs.

Figure 7 presents the maps for the data structures (A) and English (B) courses. As we can see from Figure 5, the first level can be partitioned into two parts for the data structures course and three parts for the English course. The data structures course consists of one left and one right pattern, while the English course includes two left parts that are tiled horizontally and one right part. At the second level, the data structures and English parts have the same partition results. We assigned a different color to level 3, and we assigned the leaf level according to the volume information of the node based on the categorization. Due to the fact that the same structure was used for the hierarchical structures of the data structures and English courses, the maps of these courses have the same number of levels and can thus use the same scale to display the levels corresponding to grade, semester, chapter, section, and HCUs. When the map is generated, the colors can be assigned based on the target of the application. That is, any of the cartographic rules can be applied to the target map or to maps on different scales. 


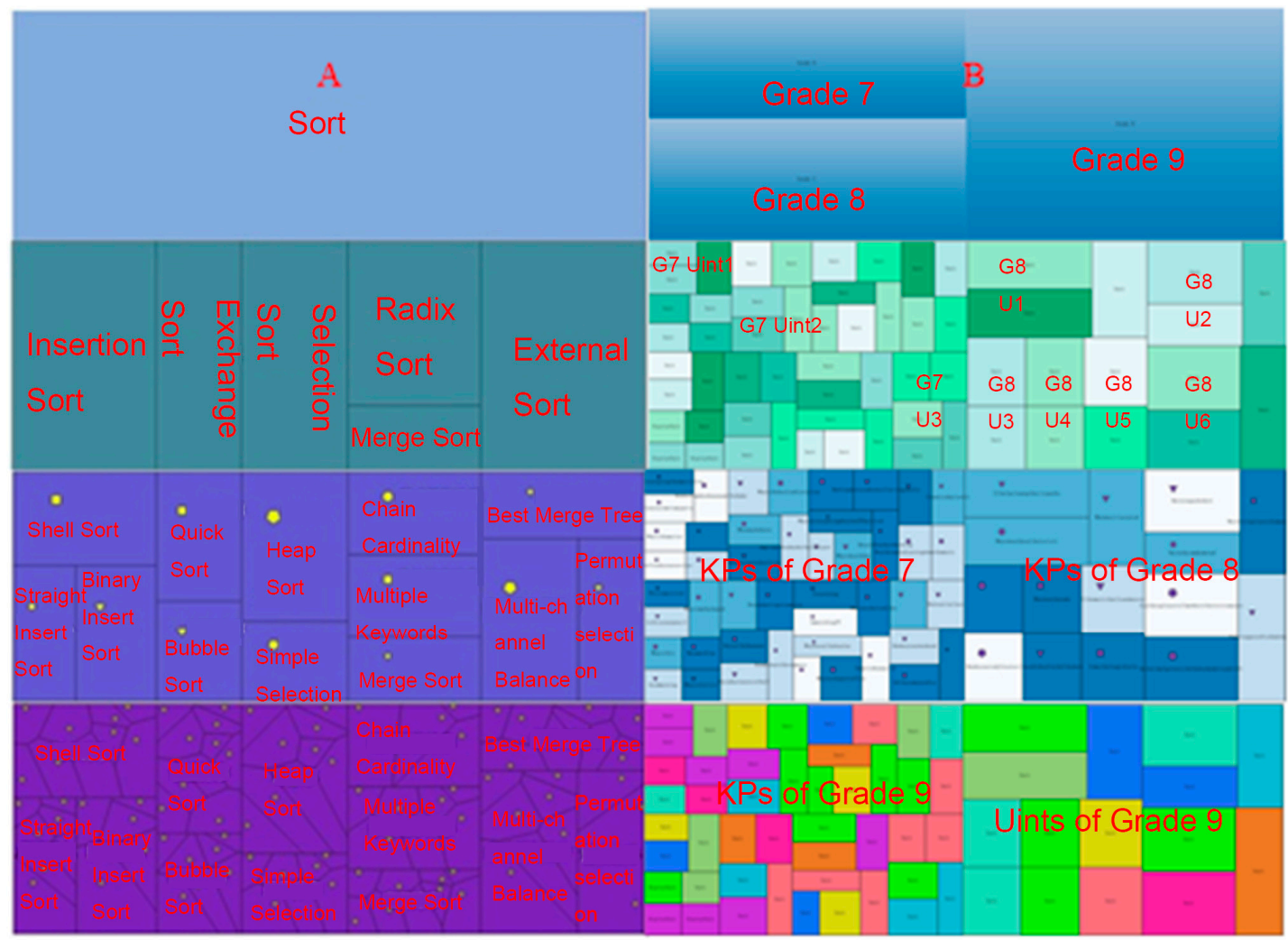

Figure 7. The maps for the data structures course (A) and the English course (B) with multiple levels.

\subsection{Analysis}

The statistical information of the test courses is listed in Table 2. The levels of the maps are the same. The regions of the resulting map differ due to the numbers of HCUs. In this test, we set the region as a rectangle by defining the upper point on the left side and the bottom point on the right side. The test map for higher mathematics covered 873 HCUs, whereas those for data structures and English covered 223 and 61 , respectively. Point $(0,0)$ is the center point for the mathematics and data structures maps, while it is the lower left point for the English map. Obviously, we could set the region for all the courses as follows: $[-180,65]$ for the top, left points and $[180,-65]$ for the bottom, right points. However, the HCUs at the finest scale would correspond to different sizes, which would introduce substantial errors in the projection when mapping this map to a spheroid-like Earth. How HCUs should be mapped to a geospatial scope should be discussed further.

Table 2. Statistics for test courses.

\begin{tabular}{cccc}
\hline Course & Map Levels & HCU & Region \\
\hline Higher Math & 5 & 873 & $\mathrm{UL}(-10,10)$ \\
& 5 & 223 & $\operatorname{DR}(-5,5)$ \\
Data Structure & 5 & 61 & $\operatorname{DR}(-5,5)$ \\
College English & 5 & $\mathrm{UL}(0,5)$ \\
& & & $\mathrm{DR}(0,2)$ \\
\hline
\end{tabular}

The tests courses were mathematics, data structures and English courses from textbooks published by China. Here, MapLevels is the number of hierarchical trees, KU is the finest knowledge unit, and Region reflects the upper-left (UL) and lower-right (DR) position in terms of longitude and latitude.

The most important attributes for the map display indicate the level of detail (LOD) at different scales. In the tree view, all the items are listed together, while in the map view, only the specific levels on certain scale can be seen. This method can achieve lower cognitive confusion and recall 
by reducing unnecessary and irrelevant information in specific circumstances. The map display can provide a more comprehensive and convenient view than the hierarchical tree view [8]. However, the intrinsically hierarchical visual features presented while zooming in and out reflect the procedures involved in cognition. Thus, presenting the hierarchical structure of knowledge to teenage students is a good choice.

The map elements are presented as polygons within the area as the background rather than as nodes and linked lines. Thus, a spaced container is provided to hold related materials and resources in separate locations in the same region, which meets the need for LBS exploration. The Google-Maps-style exploration of knowledge is acceptable for the countries, cities, and counties in a region. The geospatial mapping of hierarchical directory HCUs can achieve this functionality by assigning a region to different levels of units. By using an exploration procedure similar to that used for geospatial maps, the HCUs can be revealed widely and deeply. The geospatial map is expected to become a new mapping style for online learning systems. Therefore, applications based on geospatial maps should be further developed and tested.

The aim of this paper was to propose a universal method for map generation; thus, the serviceability of the parameters and the flexibility of the meaning for the original data are not limited in this work. Additionally, no rules about diversity were employed to check the data during preparation.

We provided three methods for partitioning the region at the finest level. The simplest and most basic method was the grid cell method. The second method was the K-D tree method, and the third method was the Delaunay method. It should be noted that partition methods are not limited to these three implementations; we merely wanted to provide variation for the map at the finest level to reduce monotonicity, especially for online learning systems based on maps.

\section{Evaluation and Discussion}

\subsection{Research Hypotheses and Methodology}

\subsubsection{Research Hypotheses}

In this study, the original technology acceptance model (TAM) was chosen as the framework of measurement to investigate the acceptance of the MapOnLearn method by two university students in China. The questionnaire consisted of three constructs: perceived usefulness (PE), perceived ease of use (PEU), and behavioral intention (BI).

Previous TAM studies have shown that perceived usefulness and perceived ease of use are key factors in predicting the acceptance and use of new technologies [53]. In this study, the perceived usefulness of MapOnLearn was defined as the degree to which the user believes that using MapOnLearn would boost his or her learning performance. The perceived ease of use of MapOnLearn was defined as the degree to which the user believes that using MapOnLearn will be effortless.

TAM assumes that perceived ease of use and perceived usefulness have a direct impact on users' attitudes towards using new technologies. Behavioral intention was defined as the degree to which a user is interested in a particular system and is considered to be a direct determinant of his or her intention to use such a system in the future [54]. The frequency of use of the system is affected by the intention of use. In addition, existing research has shown that the use of the system is also affected by perceived ease of use and perceived usefulness. Therefore, the following assumptions based on TAM were proposed:

H1: Perceived usefulness has a positive effect on the perceived ease of use of MapOnLearn.

H2: Perceived usefulness has a positive effect on behavioral intention to use MapOnLearn.

H3: Perceived ease of use has a positive effect on the perceived usefulness of MapOnLearn.

H4: Perceived ease of use has a positive effect on behavioral intention to use MapOnLearn. 


\subsubsection{Methodology}

The survey tool for this study included a nine-item questionnaire (see Table 3) to evaluate the four hypotheses of the proposed MapOnLearn. These items were based on previously published scales and were adjusted, if necessary, for the specific study context. For perceived usefulness, perceived ease of use and behavioral intention, the items used were based on the scales of Viswanath and Hillol [55].

Table 3. Items for technology acceptance model (TAM) constructs.

\begin{tabular}{cc}
\hline Constructs & Items \\
\hline PU1: Using the MapOnLearn improves understanding about the relationships of \\
the course units in my learning or teaching. \\
Perceived Usefulness \\
PU2: Using the MapOnLearn enhances effectiveness of path finding in my \\
learning or teaching. \\
PU3: I believe the MapOnLearn to be useful in my learning or teaching. \\
PEU1: My interaction with the MapOnLearn is clear and understandable in the \\
hierarchical information and relationships of the course units. \\
PEU2: Interacting with the MapOnLearn does not require a lot of my mental effort. \\
PEU3: I find the MapOnLearn to be easy to use in my learning or teaching. \\
PEU4: I find it easy to get the MapOnLearn to do what I want it to do. \\
BI1: Assuming I had access to the MapOnLearn, I intend to use it. \\
Behavioral Intention
\end{tabular}

For sample characteristics, we both used online questionnaires and conducted interviews, so the quantitative samples were mainly from Normal University, while the qualitative sample were mainly from a comprehensive university in Wuhan, China. In the sample of quantitative research, teachers and students from different courses were investigated with an online questionnaire. In total, 264 students and 27 teachers participated during the winter semester of 2019. The average age of the students was between 22 and 24 years old. The average age of teachers was 45 years. The participants are described in Table 4. A total of 291 questionnaires were issued, and 285 valid questionnaires were recovered. Six questionnaires were incompletely filled in, so they became invalid.

Table 4. Respondents of the questionnaire.

\begin{tabular}{ccccc}
\hline Disciplines & Teachers & Students & Total Number & Percentage \\
\hline Data Structure & 6 & 56 & 62 & $18.62 \%$ \\
Higher Math & 12 & 143 & 155 & $46.55 \%$ \\
College English & 9 & 65 & 74 & $22.22 \%$ \\
Total Number & 27 & 264 & 291 & 1 \\
\hline
\end{tabular}

In the sample of qualitative research of those who chose to teach this course and students who are studying this course, we interviewed four teachers and five students in the data structure course, three teachers and four students in the higher math course, and five teachers and six teachers in the college English course.

\subsection{Acceptance Evaluation}

We propose MapOnLearn, a new map organization and visualization method for online learning. However, we needed to determine if this method is useful to students and teachers. For the evaluation, both quantitative and qualitative methodologies were employed to collect data. To evaluate acceptance and intention, we used validated items to test TAM, which was developed to predict the adoption and use of new IT methods. Questionnaires based on a 7-point Likert scale (from (1) strongly disagree to (7) strongly agree) and including three items (perceived usefulness, perceived ease of use, behavioral intention use) are reliable (see Table 4). 


\subsubsection{Evaluation of Descriptive Metrics}

In this research, we applied SPSS v20 software for data analysis. The data analysis considered the core variables of TAM (i.e., perceived usefulness, perceived ease of use), along with relevant outcome variables (i.e., behavioral intention).

As shown in Table 5, our findings regarding perceived usefulness were encouraging. If MapOnLearn is useful, then students/teachers believed that it could promote learning/teaching in the courses. PU1, PU2, and PU3 for the math teachers had the highest ratings, whereas PU1 and PU3 for English teachers had the lowest ratings. We discussed these findings with several teachers and students to understand the results. They told that the map used for online learning was similar to maps used day to day and an attractive way to interact with learning materials; thus, they could easily understand and remember what they learned. In addition, the subject logic of mathematics is stronger than that of English and data structures. Furthermore, the students and teachers were curious about the new approach and showed great passion for maps. Moreover, the map service could provide students with fair and personalized learning opportunities by making all the related resources accessible through a click, allowing students to use self-pace learning and providing fair services for lifelong learning and development. Therefore, learning time increased without the students realizing it, which can perhaps improve learning efficiency.

Table 5. Items from SPSSv20.

\begin{tabular}{|c|c|c|c|c|c|c|c|c|c|c|c|c|c|c|c|}
\hline \multirow{3}{*}{ Constructs } & \multirow{3}{*}{ Items } & \multicolumn{4}{|c|}{ Data Structure Courses } & \multicolumn{4}{|c|}{ Higher Math Courses } & \multicolumn{4}{|c|}{$\begin{array}{c}\text { College English } \\
\text { Courses }\end{array}$} & \multirow{3}{*}{ CR } & \multirow{3}{*}{ AVE } \\
\hline & & \multicolumn{2}{|c|}{$\mathbf{T}$} & \multicolumn{2}{|c|}{$\mathbf{S}$} & \multicolumn{2}{|c|}{$\mathbf{T}$} & \multicolumn{2}{|c|}{$\mathbf{S}$} & \multicolumn{2}{|c|}{$\mathbf{T}$} & \multicolumn{2}{|c|}{$S$} & & \\
\hline & & $M$ & $S D$ & $M$ & $S D$ & $M$ & $S D$ & $M$ & $S D$ & $M$ & $S D$ & $M$ & $S D$ & & \\
\hline \multirow{3}{*}{$\begin{array}{l}\text { Perceived } \\
\text { Usefulness }\end{array}$} & PU1: & 5.00 & 1.91 & 5.03 & 1.79 & 5.33 & 1.25 & 5.13 & 1.66 & 4.92 & 2.02 & 4.61 & 1.24 & \multirow{3}{*}{0.81} & \multirow{3}{*}{0.63} \\
\hline & PU2: & 5.42 & 1.71 & 4.93 & 1.74 & 6.33 & 0.74 & 5.25 & 1.45 & 5.56 & 1.34 & 4.48 & 1.67 & & \\
\hline & PU3: & 5.33 & 2.05 & 5.11 & 1.38 & 5.42 & 1.71 & 5.09 & 1.64 & 4.44 & 2.59 & 4.69 & 1.30 & & \\
\hline \multirow{4}{*}{$\begin{array}{l}\text { Perceived } \\
\text { Ease of Use }\end{array}$} & PEU1: & 4.98 & 1.52 & 5.33 & 2.05 & 4.67 & 2.56 & 5.24 & 1.56 & 4.58 & 1.56 & 5.78 & 1.40 & \multirow{4}{*}{0.90} & \multirow{4}{*}{0.62} \\
\hline & PEU2: & 4.61 & 1.35 & 5.00 & 1.41 & 4.58 & 1.83 & 5.75 & 1.01 & 4.13 & 1.58 & 4.44 & 1.26 & & \\
\hline & PEU3: & 4.91 & 1.40 & 5.33 & 1.89 & 5.00 & 1.68 & 6 & 0.91 & 4.27 & 1.67 & 5.44 & 1.26 & & \\
\hline & PEU4: & 4.75 & 1.40 & 5.67 & 1.11 & 4.91 & 1.66 & 5.67 & 1.31 & 4.04 & 1.78 & 5.11 & 1.37 & & \\
\hline \multirow{2}{*}{$\begin{array}{l}\text { Behavioral } \\
\text { Intention }\end{array}$} & BI1: & 5.83 & 1.21 & 4.95 & 1.43 & 5.75 & 1.23 & 5.02 & 1.65 & 5.44 & 1.42 & 4.77 & 1.37 & \multirow{2}{*}{0.82} & \multirow{2}{*}{0.59} \\
\hline & BI2: & 6.16 & 0.90 & 4.88 & 1.32 & 6 & 0.91 & 4.94 & 1.67 & 5.33 & 1.56 & 4.52 & 1.37 & & \\
\hline
\end{tabular}

In terms of perceived ease of use, compared with teachers, more students believed that MapOnLearn was easy to use (see PEU1-4). After interviewing several teachers, we found that older teachers were not good at using information technology; such problems did not occur for young teachers. Furthermore, students are more receptive to new technologies. Maps are convenient and easy for students to use, which can promote lifelong learning and the active acquisition of knowledge to meet the needs of the individual and society.

Behavioral intention refers to the intentions of teachers and students to use MapOnLearn in the future. As described in Table 6, BI1 and BI2 for the data structures course had the highest ratings while those for English had the lowest ratings. A teacher told us that these results may be due to the nature of the data structures course: because the course is the basis of computer science, teachers of this course are likely accept new technologies to help students learn.

Table 6. The intercorrelations among constructs.

\begin{tabular}{cccc}
\hline Variables. & Perceived Usefulness & Perceived Ease of Use & Behavioral Intention \\
\hline Perceived Usefulness & - & - & \\
Perceived Ease of Use & $0.701^{* *}$ & $0.700^{* *}$ & - \\
Behavioral Intention & $0.665^{* *}$ & ${ }^{* *} p<0.001$.
\end{tabular}


The results also showed that $\mathrm{CR}$ and AVE fit their respective factors quite well. The reliability value $(\mathrm{CR})$ was above the threshold of 0.7 ; therefore, the reliability of MapOnLearn was confirmed. The average extracted variance (AVE) satisfied the recommended level of 0.5 ; therefore, the convergent validity was acceptable in the study. Both metrics indicated good internal consistency.

\subsubsection{Evaluation of Intercorrelation}

As described in Table 6, correlation analyses showed that perceived usefulness, perceived ease of use, and intention of use were highly correlated $(p<0.001)$. Hypotheses $1,2,3$ and 4 postulated that perceived usefulness has a positive effect on the perceived ease of use (H1) and behavioral intention (H2), perceived ease of use has a positive effect on perceived usefulness (H3) and behavioral intention (H4). The results showed that perceived usefulness had a moderate significant effect on the behavioral intention to use MapOnLearn $(\mathrm{r}=0.665, p<0.001)$. Perceived ease of use had a positive effect on the use of MapOnLearn $(\mathrm{r}=0.700, p<0.001)$. We also found out that usefulness had a strong positive relationship with ease of use $(r=0.701, p<0.001)$. Overall, of the four postulated hypotheses, four were confirmed in various significant levels.

\subsection{Discussion}

Combined with the questionnaire and interview of teachers and students, the usefulness and ease of use of resources represented by maps were evaluated, and the results showed that the organization of knowledge expression and resources via maps could attract teachers and students to participate in teaching or learning. Some mathematics teachers pointed out that this map method made abstract knowledge concrete, which could reduce cognitive load, and a 2D hierarchical structure was to be able to be flattened to 1D knowledge; thus, students with poor logical abilities could quickly understand the knowledge hierarchy. This method could also cultivate students' creative thinking and higher-order thinking. In addition, the location characteristics of the map organized knowledge and established the correlation between knowledge and resources; that is, the flat position of knowledge was associated with its learning resources, which enabled students to have fair and personalized learning opportunities. The map's location features could not only visualize the data with graphics and meters but also fully explored various high-quality resources for knowledge.

Although the results indicate that MapOnLearn had a certain effect on behavioral intention, the expected behavioral intention was not high due to the heavy course load and time constraints of students and the pressure put on teachers; however, an acceptable level was reached. In addition, we checked the higher education courses in China, and most courses with a textbook can be converted to a map expression. The method is also suitable for university courses. Therefore, we believe that, with the widespread application and improvement of MapOnLearn, students could be provided with richer resources and the allocation of educational resources and the ability to participate in lifelong learning could be improved.

Perceived ease of use of MapOnLearn had a positive impact on the behavioral intention of teachers and students. Through further interviews, this method was found to be conducive to teaching: not only is it a convenient representation of knowledge, but more importantly, knowledge was linked to relevant learning materials, including syllabi, slides, videos, and assignments. During the learning process, students could self-regulate according to their own progress, and subsequent learning would not be affected because they had not learned the prepared KPs. This paper concentrated on the comprehensive use of educational resources; thus, we tried to access various learning materials via click-browse behavior to improve the quality of education, promote the balanced development of education, and achieve equality and justice in education.

As for online teaching, MapOnLearn can also help the teachers in many ways. First, the map method and demo platform collected a lot of high-quality resources for the three test courses. The teachers can easily prepare the teaching materials. Secondly, the teacher can have a clear overview about what the student had learned, including the learning path and all the resources during the 
learning procedure. Third, the map-based method can support a navigating style tour teaching mode, the teaching procedure is like the tour conductor to introduce the view scene. We hope the teacher will empower more ability to support the personalized learning.

This paper focused on the generation of a map prototype, not the convenience and integrity of the whole online learning system. In other words, our method of representing learning materials can be integrated with existing learning systems. However, a map generation method is not enough. Teachers from different disciplines are also required to accept this knowledge generation and representation method and apply it. This research showed that teachers of mathematics and English have had a high degree of acceptance, and students from the digital age showed great enthusiasm for this kind of method due to its attractiveness and interactivity. Further research will improve the expression of this method and study its effectiveness in teaching.

Currently, MOOC is the dominant form for online learning. The management and presentation of resources by MOOC is mainly based on the linear structure of the course catalog. The method proposed in this study is to express the management of resources through maps. This improvement has three advantages. The first is turning linear text into schematic content can improve students' attention to a certain extent; second, the color of the map conforms to the cognitive laws of the brain, and can enhance students' impression of the knowledge framework; third, it is possible to improve learners' interest in knowledge, which unconsciously increases the length of online learning.

\section{Conclusions}

In this paper, we proposed a map method for online learning resource representation that converts the course hierarchy into a geo-referenced 2D map. The map was tested for three college courses. The map becomes a portal for online learning that can be used to locate the resources related to the course unit by a location-based map service. The visual control of map levels by scales reveals the hierarchical relationships of the courses and the units. We used topological processing and a path-finding method to represent the complex relationships between units, which is suitable for some fixed and explicit relationships. We mimicked the cognitive experience of exploring the geospatial map of a hierarchical course unit and a geographic map service, such as Google Maps. The evaluation results show that the area-based maps are suitable to serve as the basis for location-based online learning systems. Indeed, users can simply and easily receive study resources and materials related to HCUs by exploring a Google-Maps-style system. The area-based filled map is more user-friendly than the sharp shapes, dense lines, and crowded diagrams used for online learning. Thus, we hope that the mapping method can result in new styles of knowledge maps, which could lead to a new online learning style and meet the individual needs of students.

Few general rules are employed during map generation. Thus, sharp shapes, unexpected colors and unreasonable relationships among map objects are unavoidable. The rules used for map generation should be further studied and combined with 2D topological relationships to achieve a linear hierarchical tree view. High-quality organization and rich learning materials must be combined to improve courses from all disciplines.

This prototype needs to be further developed to serve online learning users of different ages, genders, and personalities by evaluating more students over a longer period in comparison with common methods. Furthermore, the effect of the map-based browsing learning style for online learning needs to be verified. We hope to carry out further testing with cognitive scientists and neuroscientists. Regarding the limitations of research design, new technologies can be used to solve these problems in the future. For the samples of quantitative and qualitative studies, the sample size was relatively small, and it was not representative of the limitations. I hope that the sample size will be expanded based on improving this method in the future.

Author Contributions: Conceptualization, S.L. and D.Z.; data curation, J.Y.; formal analysis, D.G.; funding acquisition, S.L. and D.Z.; investigation, D.Z.; methodology, D.Z.; project administration, D.Z.; resources, D.G. and J.S.; software, D.G., J.S., and D.Z.; supervision, S.L.; validation, D.G., J.S., and J.Y.; visualization, D.Z.; 
writing—original draft, D.G.; writing—review and editing, J.Y. All authors have read and agreed to the published version of the manuscript.

Funding: This research was funded by NSFC, grant number 41671377, 61937001, and supported by the National Key R\&D Program of China (2017YFB1401303), the Humanity and Social Science Youth Foundation of Ministry of Education of China (20YJC880083), and the Fundamental Research Funds for the Central Universities (CCNU20ZN007).

Conflicts of Interest: The authors declare no conflict of interest.

\section{References}

1. Li, L.Y.; Tsai, C.C. Accessing online learning material: Quantitative behavior patterns and their effects on motivation and learning performance. Comput. Educ. 2017, 114, 286-297. [CrossRef]

2. Bargel, B.A.; Schröck, J.; Szentes, D.; Roller, W. Using Learning Maps for Visualization of Adaptive Learning Path Components. Int. J. Comput. Inf. Syst. Ind. Manag. Appl. 2012, 4, 228-235.

3. Nawrot, I.; Doucet, A. Building engagement for MOOC students. In WWW'14 Companion, Proceedings of the 23rd International Conference on World Wide Web, Seoul, Korea, April 2014; Association for Computing Machinery: New York, NY, USA, 2014; pp. 1077-1082. [CrossRef]

4. Tsai, Y.-H.; Lin, C.H.; Hong, J.C.; Tai, K. The effects of metacognition on online learning interest and continuance to learn with MOOCs. Comput. Educ. 2018, 121, 18-29. [CrossRef]

5. Skupin, A. From Metaphor to Method: Cartographic Perspectives on Information Visualization. In Proceedings of the IEEE Symposium on Information Vizualization 2000, Salt Lake City, UT, USA, 9-10 October 2000; Volume 1, pp. 8-14.

6. Wang, M.; Wu, B.; Kinshuk; Chen, N.S.; Spector, J.M. Connecting problem-solving and knowledge-construction processes in a visualization-based learning environment. Comput. Educ. 2013, 68, 293-306. [CrossRef]

7. Liu, Z.; Wang, Y.; Dontcheva, M.; Hoffman, M.; Walker, S.; Wilson, A. Patterns and Sequences: Interactive Exploration of Clickstreams to Understand Common Visitor Paths. IEEE Trans. Vis. Comput. Graph. 2017, 23, 321-330. [CrossRef] [PubMed]

8. Dang, Y.; Zhang, Y.; Hu, P.J.H.; Brown, S.A.; Chen, H. Knowledge mapping for rapidly evolving domains: A design science approach. Decis. Support Syst. 2011, 50, 415-427. [CrossRef]

9. Lin, F.R.; Yu, J.H. Visualized cognitive knowledge map integration for P2P networks. Decis. Support Syst. 2009, 46, 774-785. [CrossRef]

10. Pálovics, R.; Szalai, P.; Pap, J.; Frigó, E.; Kocsis, L.; Benczúr, A.A. Location-aware online learning for top-k recommendation. Pervasive Mob. Comput. 2017, 38, 490-504.

11. Lin, F.R.; Hsueh, C.M. Knowledge map creation and maintenance for virtual communities of practice. Inf. Process. Manag. 2006, 42, 551-568. [CrossRef]

12. Fionda, V.; Gutierrez, C.; Pirrò, G. Building knowledge maps of Web graphs. Artif. Intell. 2016, 239, $143-167$. [CrossRef]

13. Lau, K.H.; Lam, T.; Kam, B.H.; Nkhoma, M.; Richardson, J.; Thomas, S. The role of textbook learning resources in e-learning: A taxonomic study. Comput. Educ. 2018, 118, 10-24. [CrossRef]

14. Sobreira, P.; Tchounikine, P. Table-based representations can be used to offer easy-to-use, flexible, and adaptable learning scenario editors. Comput. Educ. 2015, 80, 15-27. [CrossRef]

15. Boticki, I.; Baksa, J.; Seow, P.; Looi, C.K. Usage of a mobile social learning platform with virtual badges in a primary school. Comput. Educ. 2015, 86, 120-136. [CrossRef]

16. Hone, K.S.; El Said, G.R. Exploring the factors affecting MOOC retention: A survey study. Comput. Educ. 2016, 98, 157-168. [CrossRef]

17. Heradio, R.; De La Torre, L.; Galan, D.; Cabrerizo, F.J.; Herrera-Viedma, E.; Dormido, S. Virtual and remote labs in education: A bibliometric analysis. Comput. Educ. 2016, 98, 14-38. [CrossRef]

18. Asoodar, M.; Vaezi, S.; Izanloo, B. Framework to improve e-learner satisfaction and further strengthen e-learning implementation. Comput. Hum. Behav. 2016, 63, 704-716. [CrossRef]

19. Jeong, H.; Hmelo-Silver, C.E. Productive use of learning resources in an online problem-based learning environment. Comput. Hum. Behav. 2010, 26, 84-99. [CrossRef] 
20. Raes, A.; Schellens, T. The effects of teacher-led class interventions during technology-enhanced science inquiry on students' knowledge integration and basic need satisfaction. Comput. Educ. 2016, 92, 125-141. [CrossRef]

21. Chen, Y.H.; Chen, P.J. MOOC study group: Facilitation strategies, influential factors, and student perceived gains. Comput. Educ. 2015, 86, 55-70. [CrossRef]

22. Yu, B.; Silva, C.T. VisFlow-Web-based Visualization Framework for Tabular Data with a Subset Flow Model. IEEE Trans. Vis. Comput. Graph. 2017, 23, 251-260. [CrossRef]

23. Heidrich, L.; Victória Barbosa, J.L.; Cambruzzi, W.; Rigo, S.J.; Martins, M.; dos Santos, R.B.S. Diagnosis of Learner Dropout Based on Learning Styles for Online Distance Learning. Telemat. Inform. 2018, 35, 1593-1606. [CrossRef]

24. Yang, F.; Li, F.W.B. Study on Student Performance Estimation, Student Progress Analysis, and Student Potential Prediction based on Data Mining. Comput. Educ. 2018, 123, 97-108. [CrossRef]

25. Conijn, R.; Snijders, C.; Kleingeld, A.; Matzat, U. Predicting student performance from LMS data: A comparison of 17 blended courses using Moodle LMS. IEEE Trans. Learn. Technol. 2017, 10, 17-29. [CrossRef]

26. Thoms, B.; Eryilmaz, E. How media choice affects learner interactions in distance learning classes. Comput. Educ. 2014, 75, 112-126. [CrossRef]

27. Romero, C.; Ventura, S.; García, E. Data mining in course management systems: Moodle case study and tutorial. Comput. Educ. 2008, 51, 368-384. [CrossRef]

28. Caputi, V.; Garrido, A. Student-oriented planning of e-learning contents for Moodle. J. Netw. Comput. Appl. 2015, 53, 115-127. [CrossRef]

29. Auvinen, T.; Hakulinen, L.; Malmi, L. Increasing Students' Awareness of Their Behavior in Online Learning Environments with Visualizations and Achievement Badges. IEEE Trans. Learn. Technol. 2015, 8, 261-273. [CrossRef]

30. Schwendimann, B.A.; Rodríguez-Triana, M.J.; Vozniuk, A.; Prieto, L.P.; Shirvani Boroujeni, M.; Holzer, A.; Gillet, D.; Dillenbourg, P. Perceiving Learning at a Gance: A Systematic Literature Review of Learning Dashboard Research. IEEE Trans. Learn. Technol. 2017, 10, 30-41. [CrossRef]

31. Zhang, L.; Stoffel, A.; Behrisch, M.; Mittelstaedt, S.; Schreck, T.; Pompl, R.; Weber, S.; Last, H.; Keim, D. Visual Analytics for the Big Data Era-A Comparative Review of State-of-the-Art Commercial Systems. In Proceedings of the 2012 IEEE Conference on Visual Analytics Science and Technology (VAST), Seattle, WA, USA, 14-19 October 2012; pp. 173-182.

32. Weinerth, K.; Koenig, V.; Brunner, M.; Martin, R. Concept maps: A useful and usable tool for computer-based knowledge assessment? A literature review with a focus on usability. Comput. Educ. 2014, 78, 201-209. [CrossRef]

33. Tseng, S.S.; Sue, P.C.; Su, J.M.; Weng, J.F.; Tsai, W.N. A new approach for constructing the concept map. Comput. Educ. 2007, 49, 691-707. [CrossRef]

34. Chen, N.S.; Kinshuk; Wei, C.W.; Chen, H.J. Mining e-Learning domain concept map from academic articles. Comput. Educ. 2008, 50, 1009-1021. [CrossRef]

35. Sun, J.C.Y.; Chen, A.Y.Z. Effects of integrating dynamic concept maps with Interactive Response System on elementary school students' motivation and learning outcome: The case of anti-phishing education. Comput. Educ. 2016, 102, 117-127. [CrossRef]

36. Wette, R. Using mind maps to reveal and develop genre knowledge in a graduate writing course. J. Second Lang. Writ. 2017, 38, 58-71. [CrossRef]

37. Li, L.Y.; Chen, G.D.; Yang, S.J. Construction of cognitive maps to improve e-book reading and navigation. Comput. Educ. 2013, 60, 32-39. [CrossRef]

38. Balaid, A.; Rozan, M.Z.A.; Hikmi, S.N.; Memon, J. Knowledge maps: A systematic literature review and directions for future research. Int. J. Inf. Manag. 2016, 36, 451-475. [CrossRef]

39. Johnson, B.; Shneiderman, B. Tree-maps: A space-filling approach to the visualization of hierarchical information structures. In Proceedings of the AIA Conference on Architecture, San Diego, CA, USA, 22-25 October 1991; pp. 284-291. 
40. Robertson, G.G.; Mackinlay, J.D.; Card, S.K. Cone-Trees: Animated 3D Visualizations of Hierarchical Information. In CHI '91, Proceedings of the SIGCHI Conference on Human Factors in Computing Systems, New Orleans, LA, USA, April, 1991; Association for Computing Machinery: New York, NY, USA, 1991; pp. 189-194. [CrossRef]

41. De Berg, M.; Speckmann, B.; Van Der Weele, V. Treemaps with bounded aspect ratio. Comput. Geom. Theory Appl. 2014, 47, 683-693. [CrossRef]

42. van Hees, R.; Hage, J. Stable and predictable Voronoi treemaps for software quality monitoring. Inf. Softw. Technol. 2017, 87, 242-258. [CrossRef]

43. Luo, X. Knowledge Acquisition Based on the Global Concept of Fuzzy Cognitive Maps. In GCC 2005: Grid and Cooperative Computing-GCC 2005, Proceedings of the International Conference on Grid and Cooperative Computing, Beijing, China, 30 November-3 December 2005; Springer: Berlin/Heidelberg, Germany, 2005; pp. 579-584.

44. Ong, T.H.; Chen, H.; Sung, W.K.; Zhu, B. Newsmap: A knowledge map for online news. Decis. Support. Syst. 2005, 39, 583-597. [CrossRef]

45. Jones, A.; Blake, C.; Davies, C.; Scanlon, E. Digital maps for learning: A review and prospects. Comput. Educ. 2004, 43, 91-107. [CrossRef]

46. Liang, M.; Guerra, J.; Brusilovsky, P. Building Multi-layer Social Knowledge Maps with Google Maps API. In Proceedings of the Workshop on Semantic and Adaptive Social Web (SASWeb 2012), Montreal, QC, Canada, 16-20 July 2012; p. 872.

47. Jianu, R.; Laidlaw, D.H. Poster: Visualizing Protein Interaction Networks as Google Maps. In Proceedings of the VisWeek Vis-Infovis Vast, Salt Lake City, UT, USA, 24-29 October 2010; pp. 1-2.

48. Arakawa, K.; Tamaki, S.; Kono, N.; Kido, N.; Ikegami, K.; Ogawa, R.; Tomita, M. Genome Projector: Zoomable genome map with multiple views. BMC Bioinform. 2009, 10, 31. [CrossRef]

49. Brown, D.J.; McHugh, D.; Standen, P.; Evett, L.; Shopland, N.; Battersby, S. Designing location-based learning experiences for people with intellectual disabilities and additional sensory impairments. Comput. Educ. 2011, 56, 11-20. [CrossRef]

50. Barak, M.; Ziv, S. Wandering: A Web-based platform for the creation of location-based interactive learning objects. Comput. Educ. 2013, 62, 159-170. [CrossRef]

51. Zhao, G.; Lou, P.; Qian, X.; Hou, X. Personalized location recommendation by fusing sentimental and spatial context. Knowl. Based Syst. 2020, 196, 105849. [CrossRef]

52. Yang, D.; Zhang, D.; Chen, L.; Qu, B. NationTelescope: Monitoring and visualizing large-scale collective behavior in LBSNs. J. Netw. Comput. Appl. 2015, 55, 170-180. [CrossRef]

53. Davis, F.D. Perceived usefulness, perceived ease of use, and user acceptance of information technology. MIS Q. 1989, 13, 319-339. [CrossRef]

54. Sa'nchez-Franco, M.J. WebCT-The quasimoderating effect of perceived affective quality on an extending technology acceptance model. Comput. Educ. 2010, 54, 37-46. [CrossRef]

55. Venkatesh, V.; Bala, H. Technology Acceptance Model 3 and a Research Agenda on Interventions. Decis. Sci. 2008, 9, 41-42. [CrossRef]

(C) 2020 by the authors. Licensee MDPI, Basel, Switzerland. This article is an open access article distributed under the terms and conditions of the Creative Commons Attribution (CC BY) license (http://creativecommons.org/licenses/by/4.0/). 